E.L.U.A., 7, 1991, pp: 9-26.

\title{
ESPAÑOL DE AMÉRICA Y LENGUAS INDÍGENAS
}

\author{
MARÍA VAQUERO DE RAMíREZ \\ (Universidad de Puerto Rico, Río Piedras)
}

0.1. Las posibilidades de acercamiento a un tema como éste pueden ser muchas, porque, además de ser tema especialmente sugestivo, está relacionado con uno de los aspectos más estudiados y hasta polémicos de cuantos pueden presentarse en relación con las modalidades dialectales hispanoamericanas. Es tan importante este problema del indigenismo lingüístico que, incluso, el análisis de los criterios con que aparece tratado en la bibliografía del siglo XX permitiría identificar a grandes rasgos las preocupaciones esenciales de la lingüística en Hispanoamérica.

No debe sorprendernos la atención reiterada a las influencias indígenas en el español, si aceptamos, con Malkiel, que, durante muchos años, el estudio de la lengua en Hispanoamérica, eminentemente filológico, fue el mejor equivalente de los estudios humanísticos'. Y no podemos olvidar, por otra parte, que la investigación filológica, con verdadero interés en el transfondo cultural, se vuelve particularmente compleja en lo que hoy se conoce como América, conglomerado de innumerables culturas y lenguas autóctonas, más o menos importantes antes y después del siglo XV.

Enmarcar el estudio de la lengua en su contexto histórico y social, de acuerdo a estos principios filológicos, exigió de los hispanoamericanos la necesaria atención a lo indígena. Los primeros estudiosos se apoyaron en la aceptada teoría del sustrato para crear una lingüística neorrománica, cuyas bases eran las lenguas y culturas amerindias ${ }^{2}$, con efectos comparables a los de las culturas prelatinas en la vieja Romania. El resultado es de todos conocido: desde Pedro Henríquez

\footnotetext{
${ }^{1}$ Y. Malkiel, «Hispanic Philology», Current Trends in Linguistics, II.

${ }^{2}$ Baste recordar los primeros intentos de delimitación de zonas dialectales realizados por Pedro Henríquez Ureña, en 1921, tomando como base lo que él suponía había sido la extensión de las cinco
} 
Ureña o Ángel Rosenblat hasta los maestros de hoy (pasando por los innumerables diccionaristas), pocos estudiosos han dejado de atender la influencia indígena en algún aspecto del español en América.

0.2. Tema tan abarcador puede ser abordado, monográficamente, desde muchos puntos de vista. Intentaré exponer lo que me parece más importante, apoyándome en la documentación concreta de los hechos investigados, y sin renunciar, siempre que sea posible, a las observaciones oportunas sobre los criterios de investigación manejados.

0.3. Reconozco la dificultad de lo que me propongo hacer. El tema del español y las lenguas indígenas, en cualquiera de sus aspectos, se proyecta en el tiempo, en el espacio, en lo social; sus fuentes pueden ser documentales, literarias, orales; su investigación puede ampararse en lo estrictamente lingüístico o acogerse a orientaciones interdisciplinarias, como son las propuestas por las modernas etnolingüística, sociolingüística o lingüística aplicada, encargadas de recuperar, a la manera de nuestra época, la visión abarcadora del lenguaje marginada por el estructuralismo a ultranza y que, a decir verdad, nunca fue ajena a la Linguiística Románica. En otras palabras, el tema se abre, como un río, en meandros sinuosos, y se nos puede ir de las manos si no acotamos propósitos concretos y si no precisamos conceptos y puntos de vista.

0.4. Pienso que puede ser útil partir de una realidad incontrovertible: en Hispanoamérica se escribieron textos en español, de variada índole, desde los primeros años de la conquista, y la presencia léxica de las lenguas autóctonas en estos textos se ha tomado no pocas veces como reflejo fiel de la presencia léxica en la lengua oral. Acercarse a una muestra, aunque sea limitada, de dichos textos, puede servir para identificar el fenómeno de la adopción léxica y los procedimientos textuales que favorecieron la incorporación definitiva de algunas unidades autóctonas al español general o regional; pero al mismo tiempo, y al tener en cuenta los propósitos frecuentemente informativos de dichos textos, podemos entender cómo una gran cantidad de los vocablos que encontramos en ellos, y que desaparecieron, incluso, sin dejar rastro, cumplieron su función en el momento de la escritura: eran voces nuevas para nuevas realidades. Esto no anula, por supuesto, la trascendencia de los procedimientos lingüísticos puestos en marcha

familias indígenas más importantes como lenguas de sustrato: «Observaciones sobre el español de América», $R F H, 1925$. Para la significación de este estudioso en la filología indigenista, véase María Vaquero, «Pedro Henríquez Ureña y la lingüística indigenista», Cuadernos, Facultad de Humanidades, Universidad de Puerto Rico, núm. 13, Año 1985. Reproducido en Léxico marinero de Puerto Rico y otros estudios. Playor, 1986, 195-215. A Henríquez Ureña se debe la primera cala sobre el léxico indígena en el diccionario oficial: «Palabras antillanas en el Diccionario de la Academia», $R F E$ XXII (1935): 175-186. 
por los autores de estos textos, cronistas y memorialistas, para incorporar las voces inéditas a un discurso destinado a lectores ajenos a los mismos referentes; es un hecho el acierto con que estos escritores manejaron, en esta situación, el nuevo vocabulario, pero es cierto, también, que se ha confundido muy a menudo la realidad del español hablado actualmente en Hispanoamérica con la realidad del español escrito en textos del pasado. No debe llamar la atención que, de igual manera que se ha podido interpretar la literatura costumbrista y folclórica como fuente de las hablas dialectales, se haya interpretado, también, el vocabulario autóctono de los documentos y crónicas como léxico activo, olvidando las funciones específicas que pudo haber tenido tanto en el discurso literario como en el histórico. El resultado de estos olvidos ha sido en muchas ocasiones la lexicografía indígena basada en fuentes históricas (lo cual es muy importante entendido en su verdadera perspectiva), con la extendida creencia de que los diccionarios de indigenismos recogen el vocabulario indígena activo.

0.5. No hay duda, por otro Iado, de que tenemos la posibilidad de acercarnos a la lengua oral, a la lengua viva de hoy, y de someterla a métodos de análisis que dan cuenta de la variación, en todos sus niveles, tanto social como geográfica. Acercarse, por lo tanto, a los trabajos hechos recientemente sobre la vitalidad de las influencias indígenas en el español moderno de determinadas regiones, aunque son escasas, puede ofrecer la perspectiva real del fenómeno y las tendencias en marcha. Si nos acercamos a estas investigaciones sincrónicas después de haber valorado, aunque sea rápidamente, la función de las fuentes históricas que han servido de base a los lexicógrafos, es posible que se puedan aceptar más objetivamente los datos que nos ofrece la realidad linguística dialectal y que no se vea contradicción en la comparación de los resultados allegados por los dos tipos de fuentes.

Hago todas estas aclaraciones porque cada vez que he intentado ofrecer resultados de investigaciones de campo, serias, sobre este tema, más de un lector se ha sentido sorprendido, y, en algunas ocasiones, herido, por los datos objetivos expuestos, como si reconocer la objetividad de estos hechos linguísticos fuese traicionar la personalidad del español de América, que, según creo, debe su originalidad a la forma en que ha asimilado todas las influencias, autóctonas o no, fuendiéndolas en la savia idiomática común.

Debemos aceptar, sin embargo, que un problema lingüístico tan complejo como éste, ligado a aspectos de la cultura hispanoamericana, relacionados directamente, a su vez, con las propias raíces étnicas, necesita de más investigaciones en aspectos aún no conocidos, como por ejemplo la entonación. Necesitamos, además, estudios sobre regiones de las que apenas tenemos algunas noticias folclóricas o pintorescas (pienso en anchas extensiones andinas y centroamericanas, entre otras); necesitamos, también, datos confiables que 
pongan en perspectiva algo poco estudiado: las diferencias entre las huellas dejadas en el español actual por las lenguas autóctonas desaparecidas y los casos de interferencias debidas a situaciones de «lenguas en contacto», propias de poblaciones más o menos familiarizadas con lenguas indígenas vivas. Sobre muchas de estas realidades tenemos pocos informes, e incompletos, y esto será así hasta que aparezca el gran Atlas Lingüístico de Hispanoamérica de Manuel Alvar, del cual ya se ha completado el primer tomo, dedicado al Caribe Insular. Nuestra opción, en este momento, y mientras no disfrutemos del Atlas, es trabajar con una muestra de los datos confiables de que disponemos, y ofrecer, a partir de esos testimonios, algunas interpretaciones que sean científicamente válidas.

0.6. El propósito de estas páginas es, por lo tanto, contribuir con un grano de arena (la presentación crítica de los testimonios disponibles) a la comprensión de un hecho, como parece que se ha ido gestando a través del tiempo: este hecho es la irrelevancia actual del indigenismo lingüístico como rasgo definidor del español de América, hipótesis que parece se corrobora una y otra vez en los resultados obtenidos por la dialectología actual.

\section{Testimonios escritos}

1.1. Los textos escritos en Hispanoamérica desde el mismo momento del descubrimiento son las únicas fuentes que tenemos para identificar en el pasado, tanto el aspecto del español más susceptible a las influencias indígenas (el vocabulario) como la manifestación de esta influencia en la lengua escrita. Junto a los documentos producidos por y para la administración pública americana (ordenanzas, pedimentos, vedamientos), por un lado, y junto a los numerosos escritos destinados a la Corona para dar cuenta de las cosas de Indias (cartas, relaciones, memorias), existe, por otro lado, una colección de obras extensas, de difícil clasificación, conocidas como «crónicas de Indias», «mezcla viva y heterogénea de autobiografía, de testimonios ajenos y recuerdos propios, de observación de la realidad y de amor por las cosas», según las palabras ciertas de Elena Alvar ${ }^{3}$.

Dejando a un lado el polémico asunto del valor histórico de estas crónicas, la única perspectiva convincente para lo que ahora nos interesa (sigo a los autores citados) es la que nos puede dar el partir de un elemento objetivo, el textual, cuyo estudio, además, compete directamente a la labor académica. Estos textos complejos llamados «crónicas» tienen especial interés para nosotros, y para nuestro tema, porque, al margen de otras consideraciones, toda la información

\footnotetext{
${ }^{3}$ Véase su «Prólogo» a: Manuel y Elena Alvar, Cronistas de Indias. Literatura hispanoamericana en imágenes. Madrid: La Muralla, 1980.
} 
que ofrecen está condicionada «por el espejo de la lengua», y la lengua no es ninguna ficción, no es ninguna invención; está ahí, en la realidad de los textos que han llegado hasta nosotros.

1.2. Las crónicas son numerosas, y sólo unas cuantas han sido estudiadas lingüísticamente en su totalidad con el propósito de identificar en ellas los procedimientos empleados por los narradores para dar cuenta de las nuevas realidades, procedimientos entre los cuales sobresalen los mecanismos de adopción del vocabulario nuevo, aspecto en que la influencia indígena se hace notar en la lengua escrita desde los primeros años de la conquista y la colonización ${ }^{4}$.

Es Manuel Alvar quien inicia el estudio lingüístico de las crónicas de Indias con sus trabajos modélicos sobre Bernal Díaz del Castillo ${ }^{5}$, Juan de Castellanos ${ }^{6}$ y el Diario de Colón 7 Según el modelo de análisis propuesto por Alvar en estas obras, aparece, en 1981, mi estudio sobre el primer historiador de lo que hoy se conoce como Colombia y Venezuela, Fray Pedro de Aguado ${ }^{8}$, y, en 1987, una cala en la Historia de Gonzalo Fernández de Oviedo ${ }^{9}$, uno de los más tempranos cronistas de América.

Oviedo, Bernal, Aguado y Castellanos: cuatro cronistas estudiados hoy en profundidad, además de Colón, podrían servirnos para ilustrar a grandes rasgos (no puede ser de otra manera) la presencia de las lenguas indígenas en una muestra de textos escritos en Hispanoamérica en los primeros siglos de colonización ${ }^{10}$. Además, y aunque, en rigor, no se pueda calificar de cronista a

${ }^{4}$ Es ya muy conocido, y se ha repetido constantemente, que la lingüística hispanoamericana se inicia, precisamente, con la lexicografía, y con atención especial al léxico autóctono, desde el Vocabulario de las voces provinciales de la América, de Antonio de Alcedo, aparecido en 1789, hasta el más completo repertorio de voces indígenas, Amerikanistisches Worterbuch de Georg Friederici, aparecido en Hamburgo en 1960, sin olvidar, por supuesto, la enorme labor de Rufino José Cuervo (Apuntaciones críticas sobre el lenguaje bogotano, Bogotá, 1955) o las ejemplares recopilaciones de Augusto Malaret (Diccionario de americanismos, Puerto Rico, 1925, con varias ediciones posteriores y suplementos) o de Tomás Buesa (Indoamericanismos léxicos en el español, Madrid, 1965).

5 Americanismos en la «Historia» de Bernal Diaz del Castillo. Revista de Filología Española, Anejo LXXXIX, 1970.

${ }^{6}$ Juan de Castellanos. Tradición española y realidad americana. Bogotá: Publicaciones del Instituto Caro y Cuervo XXX, 1972.

7 Cristóbal Colón, Diario del Descubrimiento I y II. Estudios, ediciones y notas por Manuel Alvar. Las Palmas de Gran Canaria: Ediciones del Excmo. Cabildo Insular de Gran Canaria, 1976.

${ }^{8}$ María T[ránsito] Vaquero de Ramírez, Fray Pedro de Aguado: lengua y etnografía. Caracas: Academia Nacional de la Historia, 1981.

.9 María Vaquero, «Las Antillas en la Historia General de Gonzalo Fernández de Oviedo». Revista dè Filología Española LXVII (1987): 1-18.

${ }^{10}$ No podemos pasar por alto trabajos sobre cronistas de otros territorios, como los siguientes: de María Victoria Romero Gualda, «Tếcnica lexicográfica en la Relación del descubrimiento y conquista de los reinos del Perú», LEA X (1988): 217-224, e «Indoamericanismos léxicos en la Crónica de Pedro Pizarro», Thesaurus. Boletín del Instituto Caro y Cuervo XXXVIII (1983): 1-34. De José M. Enguita Utrilla, «El americanismo léxico en la Peregrinación de Bartolomé Lorenzo», Anuario de Lingüística Hispánica IV (1988): 127-145. De Francisco de Solano, «Lengua y cristianización indígena en la obra de Alonso de la Peña Montenegro», Les langues néo-latines 261 (1987): 49-66. 
Fray Íñigo Abbad y Lasierra, autor, en 1789, de la primera Historia de Puerto Rico ${ }^{11}$, su obra es importante por varias razones, entre ellas por ser uno de los pocos testimonios indirectos del grado de vitalidad que tenía el indigenismo lingüístico en el siglo XVIII antillano ${ }^{12}$; por esta sola razón, el texto tardío de Abbad es fuente inestimable para entender la paulatina marginación de muchas voces indígenas en el léxico activo moderno, voces que bien pueden llamarse hoy «indigenismos arqueológicos» ${ }^{13}$.

De los estudios mencionados, selecciono los correspondientes a Colón, Oviedo, Aguado y Abbad, con algunas otras referencias documentales. Los datos que pueden allegarse, para el tema que nos ocupa, a partir de estas fuentes, son punto de partida, a mi juicio, para el entendimiento de los resultados ofrecidos al respecto por la sincronía actual

1.3. La trayectoria textual empieza con Colón, ante su necesidad de hablar sobre cosas desconocidas. Antes de que nada pasara, cuando no había empezado la sucesión de hechos, era necesario captar lo externo y hablar de la naturaleza. Por eso no es casualidad que antes de «crónica» (entendida principalmente como narración en que se refieren los sucesos por orden del tiempo, esto es, como «relato» de acontecimientos, por más que se detengan los cronistas en detalles minuciosos), antes de narración cronística, no es casualidad que se hayan escrito las «descripciones» del Diario. Los «sucesos» llegarán después, pero Colón, primer testimonio americano, lo que hace es, sencillamente, lo único que podía hacer en su caso irrepetible: abrir sus sentidos y ver, oler, oír, sin dejar de observar lo que tenía delante. Por eso, como detenidamente ha explicado Alvar en su «Prólogo» al Diario del Descubrimiento ${ }^{14}$ (investigador a quien se deben las observaciones que acabo de hacer y las que siguen), el Diario de Colón representa una primera etapa necesaria de captación sensorial de la realidad, por más que el sentido observador de Colón y la función de sus observaciones se hayan entendido como inventarios sin descripción, crítica que exige de Alvar unos comentarios que resumo: claro que hace inventario Colón, pero el llamado

Para las adopciones léxico-indígenas en los primeros tiempos de la colonización, véase Humberto López Morales, «Penetración de indigenismos léxicos en el español del siglo XVI», Actas del I Simposio de Filología Iberoamericana. Zaragoza: Pórtico, 1990, págs. 137-150; del mismo autor, «Indigenismos en los textos cronísticos de Puerto Rico: índices de frecuencia y densidad», Homenaje a A. Rosenblat en sus 70 años. Caracas: Inst. Pedagógico, 1974, págs. 337-347.

11 Fray Íñigo Abbad y Lasierra, Historia Geográfica, Civil y Natural de la isla de San Juan Batista de Puerto Rico [Madrid, 1788], Río Piedras: Editorial de la Universidad de Puerto Rico, 1966.

${ }^{12}$ Sobre este punto, véase María T. Vaquero de Ramírez, «La lengua en seis textos cronísticos de Puerto Rico», Actas del 1 Simposio Internacional de la Lengua Española, Las Palmas de Gran Canaria: Ediciones del Excmo. Cabildo Insular, 1981, págs. 363-394 [Reproducido en Léxico marinero de Puerto Rico y otros estudios. Madrid: Playor, 1986, págs. 93-126].

13 María Vaquero, «El léxico indígena en el español hablado en Puerto Rico», Philologica Hispaniensia in honorem Manuel Alvar I. Madrid: Gredos, 1983, págs. 621-640, y «La lengua en seis textos cronísticos», ya citado.

14 Op.cit., págs. 9-58. 
«inventario colombino» es culminación, en el nombrar, de rigurosas observaciones previas, reflejadas en los procedimientos mismos de adopción léxica inaugurados por el almirante y puestos en juego después por casi todos los cronistas ${ }^{15}$. O sea, no estaba Colón ante un paisaje convencional, de perfiles conocidos: lo primero que había que hacer era aprehender sus elementos (seres y cosas), y darles enseguida, con el nombre, el rango de nuevas realidades definidas.

Clásico es, en este sentido, el ejemplo colombino de incorporación de canoa explicado por Alvar, primer indigenismo aceptado oficialmente en el español ${ }^{16}$. El mecanismo se repitió una y otra vez, basado en la suma de connotaciones añadidas a un término patrimonial que sirve de base en la equivalencia. Por lo clásico, ya, del ejemplo, permítanme que lo recuerde: canoa es 'almadía' (término equivalente), a la cual se añaden los siguientes rasgos: (+a) 'hecha de un árbol', $(+b)$ 'como un barco luengo', (+c) 'todo de un pedazo', (+d) 'labrado a maravilla', (+e) 'con capacidad para 40 ó 50 hombres'.

En una segunda etapa, el vocablo nuevo aparece en disyunción con el viejo connotado (canoa o almadía), hasta que puede aparecer solo, índice de su adopción definitiva y culminación del proceso, que es dar al fin el nombre autóctono que le corresponde. No siempre fue afortunada la interpretación, pero más que el desacierto en algunos casos (el caso de bohío, entendido como topónimo para 'Haití', o aje, explicado como 'ñame'), lo decisivo del Diario es que las lenguas indígenas están en él, iniciando así el testimonio escrito de sus influencias en el español.

Todas las palabras indígenas que aparecen en el Diario son palabras arahuacotaínas, familia de lenguas oída por el Almirante en sus primeros desembarcos, y primera con la cual establecieron contacto los españoles, pero no todos estos vocablos tuvieron el mismo éxito: vocablos como canoa, nocay y tuob ('oro'), por ejemplo, no dejaron rastro en el español, y de guanín ('aleación de metales') queda sólo algún derivado, por más que todos figuren en los diccionarios sin ninguna observación al respecto. Los indigenismos del Diario son trece: aje, bohío,

\footnotetext{
${ }^{15}$ Tenemos, como es sabido, dos copias diferentes del Diario: una copia autógrafa de Fray Bartolomé de Las Casas, y otra que Hernando Colón incluyó en la Vida del Almirante. Alvar considera que ambas fuentes usaron copias distintas, según se desprende del cotejo correspondiente, y supone que debieron circular copias diferentes del texto original. Hay documentación, por lo menos, de que existió una copia del manuscrito hecha en 1493, también perdida hoy. Alvar (Diario del Descubrimiento I, ya citado, pág. 9) da muchos datos respecto a las andanzas editoriales del texto, y, según los detalles de su exposición, tanto una versión italiana impresa en Venecia en 1571 como las dos españolas, basadas en aquella, del XVIII y XX, parten de la Historia de Hernando Colón escrita con prisas en 1536. La copia de Las Casas es más fiel, pues no es un resumen, y conserva el formato de «diario». Está en la Biblioteca Nacional (ms. $\mathrm{V}^{\circ} 6-7$ ) y hay en ella una edición facsímil y una transcripción por Carlos Sanz, de 1962.

${ }_{16}$ El vocablo, como es sabido, aparece en el Vocabulario español-latino de Nebrija, de hacia 1495. Véase la excelente edición facsimilar de esta obra, realizada por la Real Academia de la Lengua Española, Madrid, 1989.
} 
cacique, caona, guanín, nitayno, nocay, tuob, ají, canoa, cazabi, hamaca y tiburón. Estos indigenismos, al lado de referencias literarias y humanistas ${ }^{17}$, de comparaciones con la realidad conocida o de rastros lingüústicos meridionales, están en el texto colombino como nombres exigidos por la novedad de lo inédito, por la conveniencia de aunar voz y realidad, porque, a la hora de dejar constancia, ningun explicación podía ser más convincente de lo insólito que el nombre mismo, nunca oído.

1.4. Por su parte, el texto de Gonzalo Fernández de Oviedo, uno de los cronistas más tempranos, tiene, lógicamente, otro talante. Su obra capital es la Historia General y Natural de las Indias ${ }^{18}$, cuya Primera Parte es particularmente importante para el tema que nos ocupa. Oviedo, en esta primera parte dedicada a las islas del Caribe, se detiene en descripciones minuciosas y en comparaciones significativas, pero, aparte otros valores, me interesa anotar que es testimonio del papel decisivo de las lenguas indígenas arahuacas en el español de América, de las lenguas propias de las regiones colonizadas al principio, las antillanas. Tan significativa es esta presencia antillana en el español, frente a las demás, que ya en 1526, cuando Oviedo escribe en Madrid el Sumario, con el fin de informar al Emperador sobre las cosas de América ${ }^{19}$, nombra lo nuevo, salvo raras excepciones de presencias lingüísticas continentales, con los términos antillanos. Por eso aparecen constantemente en sus textos los vocablos insulares, algunos propios del español general: aje, areito, barbacoa, batata, batea, bejuco, bihao, bija, bohio, cacique, caney, canoa, cazabe, cibucán, comején, corí, guanábano(a), guayabo(a), guayacán, haba, hamaca, henequén, hico, hobo, hutía, jagua, macana, maíz, mamey, mangle, naboria, nigua, sabana, yuana y yuca. Cuando las cosas o los seres que debe describir, por no ser del Caribe, no se conocen con sus verdaderos nombres, y el cronista los ignora, Oviedo es igualmente minucioso en las descripciones pero no usa el vocablo autóctono; es lo que ocurre frecuentemente respecto a las descripciones de animales nativos no antillanos,

\footnotetext{
${ }^{17}$ Sobre este punto, véase: Manuel Alvar, «Relatos fantásticos y crónicas de Indias», Actas del I Simposio de Filología Iberoamericana. Zaragoza: Pórtico, 1990, págs: 13-27.

18 Publicada completa por la Academia de la Historia de Madrid, en 1851. Había aparecido en 1535 la Primera Parte, impresa en Sevilla, como él mismo dice en la «Epístola dedicatoria», tomo I, pág. 3 (Sigo la edición de la Historia al cuidado de Juan Pérez de Tudela, Madrid: Biblioteca de Autores Españoles, 5 tomos, 1959): «Vine a esta cibdad de Sevilla a la haçer imprimir». La obra consta de tres partes y en la tercera da cuenta de los años que incluye en su narración, de 1492 a 1548, esto es, los primeros cincuenta años del continente después del descubrimiento (Historia, III, Tomo V, Libro L., Cap. XXX, pág 417).

${ }^{19}$ Sumario de la Natural Historia de las Indias, 1526. En esta obra informaba a la Corona de las cosas más sobresalientes del Nuevo Mundo y sin duda preparó el camino para la concesión del cargo de «cronista oficial», cargo que le fue confirmado por el Emperador en 1532. En 1534 se le da la alcaldía de la Fortaleza de Santo Domingo, según sus propios testimonios: Historia, I, Tomo I, Libro IV, Cap. 1, pág. 89.
} 
nombrados con términos patrimoniales o creaciones, como en el caso de los llamados tigres, gatos cervales, leones pardos, raposas, ciervos, gamos, osos hormigueros, encubertados, pericos ligeros, gatos monillos, y tantos otros. O sea, el naturalista Oviedo describe con la misma minuciosidad unas y otras realidades, pero el hablante Oviedo refleja, en 1526, algo decisivo respecto a las influencias indígenas: las cosas y los seres se nombrarán con términos de las Antillas o con términos patrimoniales ${ }^{20}$. Oviedo es, por lo tanto, testimonio lingüístico de un hecho que parece aceptan los historiadores de América: la importancia que tuvo el siglo XVI como etapa en la cual se consolida «la relación con el medio ambiente», en palabras de Demetrio Ramos ${ }^{21}$, quien se refiere al fenómeno de «ecologización» como hecho paralelo al reconocido hecho biológico y explica de forma convincente el proceso de la «criollización», lograda en todos los ámbitos y conseguida como resultado de un deliberado propósito de hacer vivible, habitable, la realidad menos favorecedora, acomodándose a ella. Y la consolidación en América de este proceso parece tomar cuerpo en la Antillas, cuya situación sirve de trampolín a toda la conquista ${ }^{22}$. No desentonan estos puntos de vista expuestos desde la historia con los ofrecidos para lo lingüístico por Guillermo Guitarte en un estudio sobre las etapas del español de América ${ }^{23}$, para quien el «período de orígenes» abarca «el lapso en que la presencia española en el Nuevo Mundo está reducida a las islas y costas meridionales del Caribe». Los casi treinta años que incluye este «lapso antillano» son fundamentales, pues sirven de adaptación de hombres y lengua, que llegarán al Continente ya «americanizados», esto es, antillanizada la expresión ${ }^{24}$ y convertidos los soldados

${ }^{20}$ Es curioso lo que ocurre en algunos casos, como en cacique, cuyas equivalencias linguísticas aparecen en el texto ([cacique es] «en algunas partes queví, y en otras tiva, y en otras guajiro, y en otras de otra manera», Cap. X) a modo de información, pero una vez registrada la equivalencia regional, dirá enseguida: «los caciques y señores de esta gente», con lo cual queda claro que, por encima de las variantes regionales consignadas, está el tainismo como palabra general adoptada por la lengua conquistadora.

21 Demetrio Ramos, «Los reinos americanos y el desarrollo de su modalidad», Historia General de España y América. Madrid: Ediciones RIALP, 1984, págs. XI-XXV.

${ }_{22}$ Para detalles pormenorizados sobre inmigración peninsular en las Antillas, véase: María Vaquero, «Navarra en el Caribe: presencia lingǘstica», Segundo Congreso Internacional de Historia de Navarra, Pamplona, septiembre de 1990. Actas en prensa. Véase, a este respecto: Enriqueta Vila Vilar, «Las Antillas y la Florida en su época de internacionalización», RIALP, citado, págs. 191-232.

${ }^{23}$ Guillermo L. Guitarte, «Para una periodización de la historia del español de América», Siete estudios sobre el español de América. México: UNAM, 1983, págs. 167-182.

${ }^{24}$ Pedro Henríquez de Ureña, en el capítulo VII, dedicado a los «Indigenismos», de su libro $E l$ español en Santo Domingo, 1940, págs. 118-129, aduce testimonios importantes de la «antiflanización» del continente: «así, en Méjico dicen batata antes de aprender a decir camote, dicen ají antes de aprender a decir chile, ceiba antes que pochote, bija antes que achiote, yuca antes que guacamote, carey antes que ayote, bohío antes que jacal» (págs. 122-123). Añade, más adelante, que «Voces como henequén, maguey, maíz, tabaco, tuna, impidieron el uso de las equivalentes de las tierras continentales» (pág. 123). Es particularmente ilustrativo a este respecto el dato ofrecido en el siglo XVI por Agustín de Zárate, transcrito por Henríquez Ureña a continuación de las observaciones anteriores: «En todas las provincias del Perú había señores principales, que llamaban en su lengua 
en vaquianos o isleños, que era como decir 'entrenados' o experimentados en las cosas de Indias, frente a los recién llegados, visoños o chapetones ${ }^{25}$.

Como constatación de lo que vengo diciendo podríamos recordar los vocabularios escritos en Méjico, como el de Fray Alonso de Molina (Voćabulario en lengua castellana y mexicana, de 1571) que da como entradas del español, entre otras, las palabras taínas axí, batata, batey o canoa. O el Vocabulario manual de las lenguas castellana y mexicana, de Pedro Arenas, aparecido en México en $1611^{26}$. Este vocabulario náhuatl-español, de Arenas, es especial porque no está concebido como un diccionario al uso, con entradas ordenadas alfabéticamente, sino como una guía de conversación. Las expresiones responden a «temas» de interés («encuentros entre personas y saludos», «cómo se pregunta por cosas perdidas», etc.). No se transcriben, por lo tanto, palabras sueltas sino unidades comunicativas, y las palabras antillanas están incluidas en la conversación con toda naturalidad como palabras de la lengua española frente a la lengua náhuatl. De todo esto es testimonio, también, Fernández de Oviedo, y el otro gran cronista de este período inicial, Bartolomé de Las Casas, fuentes importantes para acercarse a los contactos primeros entre las lenguas indígenas y el español, y para deducir, de los textos, las razones de la presencia mayoritaria arahuaca en el vocabulario indígena.

A pesar de la superioridad de los textos cronísticos sobre los documentales, en cuanto a detalles e información general, es cierto, sin embargo, como señalan algunos estudiosos, que para «ir al fondo de la cuestión [lingüística] hay que

curacas, que es lo mismo que en las islas solían llamar caciques; porque los españoles que fueron a conquistar el Perú, como en todas las palabras y cosas generales y más comunes iban amostrados de los nombres en que las llamaban en las islas de Santo Domingo y San Juan y Cuba, y [de] Tierra Firme, donde habían vivido, y ellos no sabían los nombres en la lengua del Perú, nombrábanlas con los vocablos que de las tales cosas traían aprendidos». (Historia del descubrimiento y conquista del Perú, Libro I, Cap. 10). También Las Casas ofrece noticias sobre la difusión de palabras taínas a través de los españoles (Historia, III, 16) y el P. José Acosta (Historia natural o moral de las Indias, Libro V, Cap. 13) (Apud. P. Henríquez Ureña, op. cit., pág. 123, nota 2).

${ }_{25}$ Son frecuentes estos adjetivos en las crónicas. A Alvar se debe la explicación de sus valores semánticos, quien los ha recogido y estudiado en Juan de Castellanos, ya citado, pág. 52, \#54. También están en Pedro de Aguado, que opone «las gentes visoñas y chapetonas [recién llegadas a América] que no entienden los tratos, vsanças, dobleces y cautelas de las gentes de Indias» (Historia de Sta. Marta, I, pág. 181), a los hombres expertos, conocedores y veteranos, «los vaquianos o ysleños» (Historia de Venezuela, I, pág. 122; II, pág, 32). Vaquiano ( < baquiya 'restos, resíduos': los que quedaron de expediciones anteriores) coincide, según Alvar, con isleños, de Canarias, numerosos y sobresalientes en las expediciones. Chapetón (< chapín 'chanclo incómodo') por alusión al andar pesado de los atacados de niguas, recién llegados casi siempre. María Victoria Romero Gualda, «Indoamericanismos léxicos en La Crónica de Pedro Pizarro», Thesaurus. Boletín del Instituto Caro y Cuervo XXXVIII (1983): 1-34, pág. 31, aduce un texto del autor estudiado, y se inclina por el origen indígena del término vaquiano, apoyándose en Fernández de Oviedo y el Inca Garcilaso, y rechazando cl origen árabe que le atribuye Corominas.

${ }^{26}$ Uso la edición facsimilar de la primera edición de 1611, con estudio de Ascensión H. de León Portilla. México: UNAM, 1982. 
manejar los documentos de la época ${ }^{27}$, fuentes mucho menos conocidas y poco manejadas en la lingüística hispanoamericana. ${ }^{28}$

No es mucho lo que se ha investigado directamente en archivos y documentos. Respecto a la zona antillana puedo citar los trabajos históricos de Manuel Álvarez Nazario ${ }^{29}$ (en los que no es posible detenerme en este momento) y una cala que realicé hace algunos años sobre una muestra de documentos de Puerto Rico $^{30}$. Basándome en seis textos escritos en esta isla desde el siglo XVI, seguí la presencia de adopciones, triunfos y olvidos del vocabulario indígena según se manifiesta en una pequeña muestra formada por tres cartas (dos del siglo XVI y una del XVII), una memoria (el más importante documento informativo sobre la Isla, la Memoria de Melgarejo, del siglo XVI), una descripción, del XVII, y la Historia de Abbad y Lasierra, del XVIII.

Es importante la nómina de indigenismos que ofrece Abbad y Lasierra, pero lo que resulta significativo es el tratamiento individual que da a cada unidad en el discurso. En su obra aparece un importante grupo de palabras indígenas relativas a la fauna (el mayor número), a la flora, la vivienda, las costumbres y la organización social, y todo este vocabulario es importante fuente de estudio, pero lo que me interesa destacar en este momento es que, Abbad, historiador de su pasado y cronista de su época, inserta en el discurso todas estas palabras indígenas de forma diferente según estén o no vigentes en el momento de la escritura (el siglo XVIII). El vocablo indígena así presentado se proyecta con tres valores distintos: como forma arcaica, como forma en competencia y como forma adoptada, y la comparación de estos datos con los obtenidos en las calas documentales de los siglos anteriores, permite llegar a algunas conclusiones interesantes. Para darles unos cuantos ejemplos: cuando el historiador describe las diversiones y otros aspectos de la vida indígena, se refiere a «un conjunto de baile y canto que Ilamaban areito»; «los buitis eran los ministros del ídolo», y «el cemí, una deidad que tenían»; los indios, dice el historiador, «jugaban al batey,

${ }_{28}^{27}$ Guillermo Guitarte, op. cit., pág. 172.

28 En esta línea de investigación documental, realizada obligatoriamente sobre manuscritos originales si se trata de estudiar sobre todo fenómenos fonológicos (como él mismo defiende), son importantes los trabajos de Juan A. Frago Gracia: «Una introducción a la documentación del Archivo General de Indias», Anuario de Lingüística Hispánica, III, 1987, págs. 67-97.; «Yeísmo dominicano en 1569 y problemas conexos», Actas del III Congreso Internacional de El Español de América, Valladolid, 3-9 de julio de 1989 (en prensa); «El andaluz en la formación del español americano», Actas del I Simposio de Filología Iberoamericana, ya citado, págs. 78-96.

${ }^{29}$ Véase, sobre todo, de este autor, Origenes y desarrollo del español en Puerto Rico (Siglos XVI y XVII). Río Piedras: Editorial de la Universidad de Puerto Rico, 1982, págs. 361-378.

${ }^{30}$ María Vaquero, «La lengua en seis textos cronísticos de Puerto Rico (Contribución al estudio del español antillano)», Actas de I Simposio Internacional de la Lengua Española (1978), Las Palmas de Gran Canaria: Ediciones del Excmo. Cabildo Insular, 1981, págs. 363-394. Reproducido en Léxico marinero de Puerto Rico y otros estudios, ya citado, págs. 93-126. Esta cala se realizó a partir de los documentos publicados por Aida R. Caro Costas, Antología de Lecturas de Historia de Puerto Rico (Siglos XV-XVIII), Editorial Universidad, Universidad de Puerto Rico, 1977. 
tenían caneyes, usaban cayucos, sembraban en conucos, y bebían en múcuras». $\mathrm{Y}$ frente a estos arcaísmos, proyectados en el discurso de Abbad a través del tiempo verbal pasado, los naturales contemporáneos «cuelgan sus hamacas en una pieza de la casa destinada a dormitorio" y duermen en unas camas, descritas por el cronista, «que llaman barbacoas».

Sobran en el texto, naturalmente, las explicaciones de todas las palabras que, en el siglo XVIII, ha incorporado la lengua a su léxico, como unidades generales o regionales: achote, batata, cacao, cacique, caribe, cazabe, huracán, maí, nigua, piragua o tabaco. Y, por supuesto, están ausentes muchos vocablos que aparecen en los documentos del pasado; en su lugar aparecen los criollismos o adaptaciones, por un lado, $y$, por otro, las palabras y frases de la lengua patrimonial, triunfantes en la competencia, que acabaron imponiéndose en el uso: «planchuelas de oro» sustituye a chaguala, el adorno caribe que se colgaban los caciques al cuello; los 'colgantes de nariz' son aquí «caracolillos», no caricuríes, y las peleas son «escaramuzas, encuentros o refriegas», no guazárabas. Hasta bohío aparece teñida de cierto matiz arcaico y rústico (son «casas pajizas»), y los arcabucos, que tanto aparecen en los documentos anteriores, son ahora «bosques espesos», donde las mujeres se cubren con «delantalillos» mientras preparan el cazabe en una «horma de barro», no en el burén.

Sin embargo, y a pesar de estos testimonios de anacronismo en el XVIII, chaguala, y guazáraba, y burén, y buiti, y caney o arcabuco, entre tantas otras, aparecen en los diccionarios actuales, dando la impresión de que son vocablos en uso, cuando la realidad es que muy pocas personas las conocen en nuestros días.

1.5. Volviendo al pasado, la enorme obra escrita por Fray Pedro de Aguado ${ }^{31}$, otro de los cronistas que vale la pena tener en cuenta, puede documentar sobradamente la presencia significativa de vocablos antillanos en el siglo XVI frente a la escasez de los continentales. A pesar de que la crónica de Aguado abarca los territorios propios de las culturas chibcha y caribes continentales, de 114 indigenismos que he recogido en su obra, 43 son tainismos (el 38\%), dato que corrobora la difusión del vocabulario antillano junto con la lengua conquistadora, frente a la pobre representación quechua, con sólo cinco voces $(4 \%)$, e incluso náhuatl, con cuatro (3.5\%). Algo parecido ocurre con la lengua de los chibchas, cuya pobre representación de 14 términos (12\%) en tan extenso número de páginas escritas en su propio territorio, tiene que ver sobre todo con

${ }^{31}$ La Historia de Santa Marta y Nuevo Reino de Granada, correspondiente a la «Primera Parte» de la Crónica, aparece completa por primera vez en Madrid, en dos volúmenes, en 1916-17, y la Historia de Venezuela, correspondiente a la «Segunda Parte», en otros dos, apareció en 1918-19, Ias dos a cargo de Jerónimo Bécker. Parece que el manuscrito de la «Primera Parte» estaba completo en 1575 , pues alude a él en su «Probanza de Servicios»; en 1579 ya aparecen redactadas las dos partes, pues las tiene en este año el cosmógrafo de Indias Juan López de Velasco para la revisión, y en 1581 82 el rey otorgó las cédulas de impresión, aunque no llegaron a imprimirse. 
conceptos religiosos (mohán, 'sacerdote'; moque, 'resina para sahumerios'; tunjo, 'ídolo' o xua, 'hijos del sol' = españoles). Pocas de estas palabras podrían permanecer en el uso de una sociedad que adoptó, con las nuevas creencias, el vocabulario español de la cristiandad, y pocas fueron también las que triunfaron en fauna y flora, frente al empuje de las demás lenguas de prestigio general. Por eso, cuando, al hablar de una fruta, Aguado escribe «algunos las llaman peras, por tener alguna similitud dellas, y otros las llaman curas, y otros paltas» (Sta. Marta, II, pág. 172), es fácil darse cuenta de cómo el vocablo chibcha cura, aunque pueda estar en vocabularios y diccionarios, respaldado incluso por la cita de esta autoridad del XVI, es hoy vocablo desconocido para la mayoría de los hispanoamericanos. La fruta que Aguado explica comparándola con «pera» se llama hoy aguacate, en los países del Norte del Ecuador, término náhuatl que luchó, en un principio, con la española, y en los territorios del Sur, el árbol se llama palto, y la fruta palta, voz de origen quechua. Y como cura, tantas otras, de lenguas hoy olvidadas, que acabaron por desaparecer.

1.6. En esta primera parte de mi exposición, me he detenido en los textos que conozco un poco mejor, aunque, como decía al principio, podríamos citar a cronistas importantes como Bernal, Castellanos, o Las Casas, que sin duda manejan cantidades considerables de indigenismos. Baste lo dicho para apuntar que estas relaciones ofrecieron sin duda el inventario enorme de palabras que ha servido de fuente principal a la hora de redactar los diccionarios y vocabularios hispanoamericanos. $\mathrm{Y}$ es importante reconocer que, incluso, en las mismas crónicas hay indicios del desuso en que estaban muchas palabras consignadas; si aparecen en el texto es porque los cronistas escriben para dar cuenta y noticia de las realidades sociales y culturales de la manera más completa posible, siendo los nombres autóctonos el elemento que dota de autenticidad a las cosas descritas y expuestas. La mayoría de los voluminosos diccionarios de indigenismos, redactados a partir de estas fuentes, son importantes e imprescindibles diccionarios históricos, no diccionarios de léxico activo, con porcentajes considerables de entradas desconocidas por los hablantes.

\section{Lenguas indígenas y estudios dialectales}

2.1. Tan recientemente como en 1990, con ocasión del I Simposio sobre Filología Iberoamericana, Eugenio Coseriu pronunciaba en Sevilla estas palabras, que vale la pena transcribir y leer:

Todo lo general, todo lo esencial, todo lo sistemático, todo lo que tiene vigencia super-regional (y también muchísimo de lo local: casi todo) en el español de América, al menos en los planos en que hay que buscar la unidad idiomática y cabe 
aspirar a ella, es español sin adjetivos delimitadores. El influjo indígena y el de otras lenguas conciernen casi sólo a aspectos superficiales del idioma y sólo tienen vigencia regional o estrictamente local: y en los pocos casos en que alcanzan el nivel del sistema lingüístico (así algunas veces en el ámbito fónico), conciernen a comunidades hasta hace poco, o todavía, bilingües $y$, por lo común, inestables y de límites muy imprecisos, comunidades indígenas sólo superficial o parcialmente hispanizadas, o primeras y - muy rara vez- segundas generaciones de inmigrantes. ${ }^{32}$

Para llegar a estas observaciones de hoy, desde los tiempos de Rodolfo Lenz, con su famosa hipótesis de que en Chile se hablaba «español con sonidos araucanos $»^{33}$, han tenido que pasar cien años, decisivos para la comprensión objetiva de lo hispanoamericano y de su verdadera originalidad.

Superada la etapa de exaltación sustratística ${ }^{34}$, en boga a principios de siglo, la investigación dialectal venía dando llamadas de atención respecto a las influencias indígenas reales en el español de América ${ }^{35}$. Amado Alonso, traductor del trabajo decimonónico de Lenz, representa, en $1939^{36}$, un decisivo cambio de actitud, cambio que cristaliza, con datos concretos, en otro lingüista prominente, Bertil Malmberg, autor de varios trabajos definitivos al respecto ${ }^{37}$. Malmberg, interesado en lo fónico, desmonta uno a uno los argumentos sustratísticos a favor de las peculiaridades fonéticas de alcance hispanoamericano, salvo para unos cuantos fenómenos que no es posible explicar por causas internas (como la pervivencia de la líquida palatal en tierras del Paraguay) $)^{38}$. Las influencias indígenas

${ }^{32}$ Eugenio Coseriu, «El español de América y la unidad del idioma», Actas del I Simposio de Filologia lberoamericana, ya citado, págs. 43-75. Confr. pág. 62, \#5.21.

${ }_{33}$ Rodolfo Lenz, «Beitrage zur Kenntnis des Amerikanospanischen», ZRPh XVII (1893): 188 214. Traducción española de A. Alonso y R. Lida, «Para el conocimiento del español en América», BDH VI (1940): 209-258, pág. 249.

${ }_{34}$ Véase, en este punto, Marius Sala, «Evolución interna o influencia externa en el español de América», Plenaria, Actas del I Congreso sobre El Español de América, ya citado, págs. 187-208.

35 Para entender ciertas actitudes de un estudioso como Henríquez Ureña, hay que tener en cuenta la época en que vive; su compromiso con lo hispanoamericano lo lleva a defender posturas que le parecieron favorables a la defensa de la originalidad cultural. No es casualidad que, lo mismo combate apasionadamente el andalucismo, se ampare en las lenguas indígenas para marcar modalidades dialectales y dedique estudios ejemplares al vocabulario autóctono, en busca de identidad. Véase, sobre la actitud de Henríquez Ureña y su interpretación, acomodaticia, de Cuervo: Guillermo Guitarte, «Cuervo, Henríquez Ureña y la polémica sobre el andalucismo de América», Vox Románica, XVII (1958): 363-416. (Reproducido en Siete estudios sobre el español de América. México: UNAM, 1983, págs. 11-61).

36 Amado Alonso, «Examen de la teoría indigenista de Rodolfo Lenz», RFH 1 (1939): 313-350.

37 «L'Extension du Castillan et le probleme des Substrates», Actes du Colloque International de Civilisations, Litteratures et Langues Romanes. Bucarest, 1959, págs. 249-260; «Tradición hispánica e influencia indígena en la fonética hispanoamericana», PFLE II (1964): págs.227-243; etc.

${ }^{38}$ Existe un aspecto fonológico, ya citado, que habrá que atender, la entonación, rasgo dialectal apenas estudiado que puede ofrecer algunos datos interesantes de interferencia entre hablantes bilingües. Los siguientes estudiosos han llamado la atención sobre posibles influencias indígenas en lo prosódico: J.A. Suárez, «Indigenismos e hispanismos, vistos desde la Argentina», Romance Philology 
fonéticas, decisivas para Lenz, quedaban bastante mal paradas a la luz de los marcos teóricos estructurales proyectados, además, sobre investigaciones de lo sistemático cada vez más rigurosas. ${ }^{39}$

2.2. En cuanto a las influencias morfosintácticas, descontando los fenómenos ofrecidos en los manuales clásicos de Alonso Zamora Vicente o de Rafael Lapesa, apenas tenemos noticias, y habría que anotar, por otra parte, lo que ya se ha venido reconociendo con insistencia: estos fenómenos morfosintácticos son más bien interferencias propias de comunidades bilingües o familiarizadas con lenguas indígenas, y no característicos del español de América; ni siquiera son propios, en muchos casos, de las modalidades hispánicas regionales en que se insertan estas comunidades bilingües.

Son interesantes los fenómenos de topicalización que ya Toscano Mateus ${ }^{40}$ presentó en 1953 y que recuerda Marius Sala ${ }^{41}$ como ejemplos de influencias indígenas en la sintaxis ecuatoriana, si bien debemos esperar, en esto como en otro aspectos, los datos que nos ofrezca el Atlas lingüístico de Hispanoaméric $a^{42}$, gran proyecto dirigido por Manuel Alvar, que mostrará el grado de vitalidad de no pocos fenómenos aducidos en el pasado y en el presente. El fenómeno de topicalización a que me refiero, se manifiesta en el orden de la pregunta ¿qué para hacer? en lugar de ¿para hacer qué?, ejemplo de orden sintáctico a la manera quechua ${ }^{43}$.

20 (1966-67): 68-90; E. Vidal de Battini, El habla de San Luis, Parte I: Fonética, Morfología, Sintaxis. Buenos Aires, 1940; B. Malmberg, «L'Espagnol dans le Nouveau Monde. Probleme de Linguistique Generale». Studia Linguistica 1 (1947): 79-116; 2 (1948): 1-36. Sobre entonación dialectal con metodología moderna, véase A. Quilis «Entonación dialectal hispánica», Plenaria, Actas del I Congreso Internacional sobre El Español de América (San Juan, 1982), editadas por H. López Morales y M. Vaquero, Academia Puertorriqueña de la Lengua Española, 1987, págs. $117-$ 164.

39 México es una de las regiones más estudiadas desde el punto de vista de las influencias indígenas en lo fónico. Son importantes los trabajos de J.M. Lope Blanch recogidos en Estudios sobre el español yucateco. México: UNAM, 1987, y los de Manuel Alvar, «Nuevas notas sobre el español de Yucatán», Iberorrománica I, págs. 159-189, quien, después de rigurosas observaciones, afirma: «el español yucateco se encuadra fonológicamente con el español de toda la República y, aún más, con los rasgos generales del español de América, aunque presenta su originalidad dentro de las posibilidades que permite la unidad, ya que no la uniformidad» (pág. 184). A conclusiones muy semejantes llegó el profesor Alvar sobre «Algunas cuestiones fonéticas del español hablado en Oaxaca (México)», NRFH XVIII, 3-4, págs. 353-377. Rafael Lapesa, Historia de la lengua española, ha ido anotando en sus recientes ediciones las últimas investigaciones sobre este tema. Véase su capítulo XVII, «El español de América», y dentro de él, el apartado \#127, «Las lenguas indígenas y su influencia», con bibliografía actualizada.

${ }^{40}$ H. Toscano Mateus, El español en el Ecuador. Madrid, 1953.

$4 !$ Op.cit., pág. 198.

${ }^{42}$ Véase el Cuestionario correspondiente, de M. Alvar y A. Quilis, Madrid: ICI, 1984. Está en prensa el primer volumen, dedicado a El Caribe Insular, y en preparación el segundo, dedicado a América Central. Las encuestas en Ecuador y otras regiones andinas se han completado.

${ }^{43}$ Lope Blanch, «La lengua española. Variedades dialectales del español mexicano e influencia de las lenguas amerindias en el español de México», en Las lenguas de México II, México, 1975, 
2.3. El aspecto del español de América en que la inflluencia indígena parece aún indiscutible es el del vocabulario, apariencia respaldada por las listas enormes de palabras recogidas en los diccionarios generales y regionales, como he venido diciendo. Sin embargo, ya en 1963 se refería Morínigo a «la gran masa de voces indígenas que constituyen en ellos [los diccionarios] un peso muerto en el mejor de los casos», e incluso explicaba las razones eruditas de los lexicógrafos, empeñados en demostrar «el conocimiento de la historia del país o su conocimiento de las lenguas indias, que en algunos casos están aún vivas». ${ }^{44}$

Cuando en 1969, Juan M. Lope Blanch se decide a estudiar rigurosamente la vitalidad del léxico indígena nada menos que en México, partía de una hipótesis afín con las ideas citadas de Morínigo y corroborada después en su propia investigación: «la erudita acumulación de palabras prehispánicas en los diccionarios de americanismos no responde a la realidad hablada ${ }^{45}$. La revisión del Diccionario de aztequismos de Robelo ${ }^{46}$ le permitió obtener un dato significativo: del millar y medio de nahuatlismos que aparecen en él, sólo unas 160 formas habían sido reconocidas por los mismos investigadores del equipo que iniciaba el estudio bajo su dirección, o sea, poco más del $10 \%$, y sólo unas 250 eran las que unos u otros conocían con alguna precisión, sin olvidar que muchos de estos vocablos conocidos son de carácter general en el español moderno (chocolate, tomate, chicle, etc. $)^{47}$. El caso no es único e incluso los hay más violentos, como es el contraste - -sigo a Lope Blanch — entre las palabras recogidas por Lisandro Alvarado para Venezuela ${ }^{48}$ y las usadas por el hablante venezolano. Según los estudios de Angel Rosenblat ${ }^{49}$, el hablante venezolano sólo conoce 17 de las 1700 voces recogidas por Alvarado. Se evidencia ya en estos estudios lo que presentaba al principio: los glosarios y diccionarios de indigenismos son en realidad diccionarios históricos, cuyas fuentes han sido en realidad «las autoridades» del pasado (historiadores, cronistas, viajeros, naturalistas) o los escribanos de cartas y memoriales. La gran importancia de estos diccionarios está en que son instrumentos imprescindibles a la hora de acercarse a los textos, pero nunca deben interpretarse como

págs. 129-172, ha consignado casos de topicalización indígena del tipo «Cruz loma», «loma de la Cruz», o «mula corral», «corral de la mula».

44 «La penetración de los indigenismos americanos en el español», PFLE, Madrid: 1963, Tomo II, pág. 226.

45. Juan M. Lope Blanch, El léxico indígena en el español de México, El Colegio de México, 1969. pág. 18.

${ }^{46}$ Cecilio A. Robelo, Diccionario de aztequismos, o sea jardín de las raíces aztequismos. México, s.a.

${ }^{47}$ Alude Lope Blanch al empeño de Robelo por dar, incluso, como indígenas palabras hispánicas; es el caso de cogote, cochino, apachurrar o nana, dato que corrobora improvisación al preparar sus materiales. Cogote ya aparece en el Universal vocabulario de Alonso de Palenciá, publicado en Sevilla en 1490.

${ }^{48}$ Lisandro Alvarado, Glosario de Voces Indígenas de Venezuela. Caracas, 1921.

${ }^{49}$ El castellano de Venezuela. 
repertorio de unidades activas, que es lo que se ha hecho frecuentemente en Hispanoamérica.

Hoy contamos con cuatro investigaciones sobre «conocimiento y uso de indigenismos», incluyendo el trabajo citado de Lope Blanch para México: me refiero a las investigaciones de López Morales para $\mathrm{Cuba}^{50}$, las de Orlando Alba para Santo Domingo ${ }^{51}$ y las mías para Puerto Rico ${ }^{52}$. López Morales parte de Pichardo ${ }^{53}$ y de Tomás Buesa Oliver ${ }^{54}$; Orlando Alba parte de la nómina ofrecida por Henríquez Ureña ${ }^{55}$, y mi trabajo partió de Luis Hernández Aquino ${ }^{56}$.

El trabajo de mayores proporciones es el de Lope Blanch, pues consigna la acepción y vitalidad de los indigenismos de México recogidos de la lengua espontánea, oral, y de la lengua escrita moderna. En un corpus léxico total, con un número aproximado de 4.600 .000 palabras (50\% relativas a lengua oral y $50 \%$ a la escrita), sólo 3.384 palabras corresponden a indigenismos comunes, reducidas a sólo 238 raíces indígenas. Esta cifra representa en México la pobre cantidad de menos del $1 \%$ de indigenismos frente al vocabulario de origen hispano.

Tanto este trabajo sobre México como los otros tres sobre Cuba, Santo Domingo y Puerto Rico, deslindaron y eliminaron cuidadosamente antropónimos, topónimos y gentilicios, unidades que, como es bien sabido, no forman parte del léxico que podemos llamar funcional y común. Tanto Alba como López Morales llegan a resultados muy semejantes: de todos los indigenismos que aparecen en el gran diccionario de esteban Pichardo, más los ofrecidos por Buesa Oliver, sólo 97 pueden considerarse vivos en el español de Cuba; en cuanto a Santiago de los Caballeros, del inventario ofrecido por Henríquez Ureña para Santo Domingo, sólo viven 107 palabras.

50 «Indigenismos en el español de Cuba», Estudios sobre el español de Cuba, New York: Las Américas Publishing Company, 1971, págs. 50-61.

51 «Indigenismos en el español hablado en Santiago», Anuario de Letras XIV (1976): 71-100.

52 María Vaquero, «El léxico indígena en el español hablado en Puerto Rico», Philologica Hispaniensia in honorem Manuel Alvar I, Madrid: Gredos, 1983 (Reproducido en Léxico marinero, ya citado, págs. 127-151, seguido de los «Índices» correspondientes, págs. 153-193); «Indigenismos y variables sociolingüísticas», en Homenaje a J.M. Lope Blanch, México: UNAM, en prensa.

${ }_{53}$ Esteban Pichardo, Diccionario provincial de voces cubanas [1² ed. Matanzas, 1836], 1953.

$54 \mathrm{~T}$. Buesa Oliver, Indoamericanismos léxicos en el español. Madrid: CSIC, 1965. De esta obra selecciona los vocablos que, por generales, no aparecen en el diccionario de Pichardo.

${ }^{55}$ En el «Capítulo VII» de El español en Santo Domingo, 1940.

${ }^{56}$ Diccionario de voces indígenas de Puerto Rico, Río Piedras: Editorial Cultural, 1969 [Segunda edición 1977]. Para los estudios sobre el tema en la Isla, véase su «Lexicografía indígena de Puerto Rico», Discurso de incorporación a la Academia Puertorriqueña de la Lengua Española, BAPLE VIII/ 1 (1980): 25-49.

Manuel Álvarez Nazario ha dedicado un exhaustivo estudio a El influjo indígena en el español de Puerto Rico, Río Piedras: Editorial Universitaria, 1977. Es una obra erudita en que of rece etimologías y estudios históricos minuciosos sobre cada palabra. Este mismo autor tiene trabajos sobre las lenguas arahuacas y su pervivencia actual, así como innumerables referencias al tema en sus muchos estudios sobre la lengua de Puerto Rico. 
Parecidas conclusiones ofreció mi estudio sobre Puerto Rico, investigación de campo que abarcó toda la isla, y midió el grado de conocmiento y uso de los 183 indigenismos comunes sometidos a una muestra estratificada según las variables de sexo y nivel socio-cultural, cuyos informantes debían contestar, de cada palabra, si la conocían, si la usaban, y el significado o significados que le daban.

Sólo una, cuisa, fue totalmente desconocida, pero, de las 182 restantes, 82 fueron reconocidas por menos del $50 \%$ de los informantes, razón por la cual se consideraron fuera del uso común y es importante añadir que de estas 82,45 , casi la mitad, fueron reconocidas por una mínima parte de los hablantes, sólo del I al $10 \%$. Las 100 palabras conocidas y usadas por más del $50 \%$ representan el $55 \%$ del total de unidades del diccionario de Hernández Aquino, poco más de la mitad.

Como era de esperarse, los universos con mayor número de unidades son los relativos a plantas y animales, donde se encuentran numerosos indigenismos conocidos y usados por el mayor número de hablantes. El 100\% reconoció, naturalmente, los indigenismos generales en español y los generales en la Isla (guayaba, yautía). Los hombres conocen y usan más los relativos a fauna y flora; las mujeres, por su parte, saben y usan vocablos indígenas relativos a especias y semillas para condimento. Son escasos los instrumentos de labranza nombrados con indigenismos, así como casi inexistentes los nombres autóctonos de comidas y creencias.

Parece justo reconocer, para terminar, lo que los grandes maestros hispanoamericanos intuyeron y propusieron respecto a las influencias indígenas, incluso en el vocabulario, aspecto que parece ser el más teñido por lo autóctono. Hoy ya no es necesario aferrarse a las influencias indígenas, más o menos justificadas, para defender o probar la originalidad del español de Hispanoamérica: ahí está el mosaico de las modalidades que lo integran como un conjunto de variedades en la unidad idiomática, con todo el dinamismo del sistema, capaz de asimilar las influencias más dispares, incluidas las autóctonas, y de convertirlas en particularidades propias dentro de la lengua histórica que llamamos español moderno, proyectado hacia el futuro desde la savia común. 